\title{
Emotional Intelligence Levels of Students with Sensory Impairment
}

\author{
Suhair Al-Tal ${ }^{1}$, Fuad AL-Jawaldeh ${ }^{1}$, Heyam AL-Taj ${ }^{1} \&$ Lina Maharmeh $^{1}$ \\ ${ }^{1}$ Psychology, Counseling \&Special education, Amman Arab University, Jordan \\ Correspondence: Suhair Al-Tal, Psychology, Counseling \&Special education, Amman Arab University, Jordan. \\ E-mail: suhair_hail2002@hotmail.com
}

Received: February 26, 2017

Accepted: March 31, 2017 Online Published: July 29, 2017

doi:10.5539/ies.v10n8p145

URL: https://doi.org/10.5539/ies.v10n8p145

\begin{abstract}
This study aimed at revealing the emotional intelligence levels of students with sensory disability in Amman in Jordan. The participants of the study were 200 students; 140 hearing impaired students and 60 visual impaired students enrolled in the special education schools and centers for the academic year 2016-2017. The study adopted the descriptive Approach. To achieve the goals of the study, the researchers prepared an emotional intelligence scale consisted of 30 items distributed into four fields: emotional knowledge, emotion regulation, empathy, and social efficiency. The scale's reliability and validity were verified. Results showed that the total degree of the emotional intelligence of the students with hearing impairment was low and it was moderate for the students with visual impairment. Additionally, results revealed statistical significant differences between the students with hearing impairment and students with visual impairment in all the fields in favor of the students with visual impairment.

The study confirmed the necessity to encourage people with sensory disabilities to take part in well-prepared activities and programs that allow them to express their emotions freely as drawing, acting, music and others to develop their emotional intelligence.
\end{abstract}

Keywords: emotional intelligence, sensory disabilities

\section{Introduction}

The emotional intelligence is a good predictor of the person's success in his practical life rather than the whole intelligence which is only a good predictor for the individual's academic success. The people who are highly emotional intelligent are too close to achieve success in their life. The emotional intelligence helps in constructing the individual's personality to be more successful and enjoyable (Al-Hadidi, 2013). The visual and hearing impairments influence is felt in the mental growth and development through affecting the intelligence and the mental capabilities as the intelligence play $\mathrm{s}$ major and effective role in developing the individual's personal and social capabilities. When the intelligence's degree gets higher, its capability of compatibility increases and the adaption reflects intelligence limitation of some people with disabilities and therefore their life becomes more complicated surrounded by lack of confidence and depression (Al-Zreigat,2009).

Many studies were conducted in the Arab region about the emotional intelligence of people with impairment. But this study is distinguished for examining the sensory impairment; hearing and visual. Additionally, this study identified the emotional intelligence levels of the students with hearing and visual impairment in light of gender variable and studied the differences between these levels.

The hearing impairment: There are many definitions for the hearing impairment including the functional definition which relies on the extent to which the degree of hearing loss affects realization and understanding the verbal language. Based on this definition, Soliman (2007) believes that the hearing impairment means a deviation in hearing that reduces the ability of oral and verbal communication.

The hearing impairment: many definitions have appeared concerning the hearing impairment including the functional definition that relies to which extent the hearing loss affects understanding and realizing the spoken language. And based on this definition, Abd-hameed (2009) believes that the visual disability means a deviation of the hearing that hinders the capability of the verbal and hearing communication. The concept of the hearing impairment highlighted the hearing problems which its strength ranges from mildness to moderate and it is called "hard of hearing" and from moderate till severe which is known as deafness. When the degree of hearing loss is more than 70 decibels, the individual or the person cannot hear with, without using instruments (Al 
Jawalda, 2012)

The visual impairment: it is uncommon disability compared to other disabilities. According to the Education office of the visual impaired people in USA, the proportion of the visual impaired people is about $1 \%$ of the population representing $5 \%$ of the different special education categories (Jarwan, 2012).

The visual impairment has many definitions as:

- Legal definition: from the medical point of view, the blind person is the person whose vision is less than $20 / 200$ feet. In other words, the thing which the normal person sees 200 feet away should be closer 20 feet for the blind.

- Educational definition: the blind person is the one who can only read, or write using Brail method. Paraga also defined the blind person as the one who needs changes and adjustments in the educational materials, methods of teaching and the environment school (Soliman, 2007).

- Functional definition: Harly defines the blind person as the one whose disability degree obliged him to use Brail Method (Al-Jawalda, 2002).

The emotional intelligence: the concept of emotional intelligence appeared when Goleman published his first book in 1995 and since then this concept has started to take its significant place in the educational institutions (Ghobari \& Abo Shareah, 2010). Golman defined the emotional intelligence as: "the person's ability to recognize positively and effectively his own and others' feelings, self motivation, emotional regulation and social relations including self-control, enthusiasm, perseverance and determination (Golman, 1995, p. 16).

The emotional intelligence is considered a part of the social intelligence and they both share some concepts as realization and empathy but the emotional intelligence is more comprehensive than the social intelligence because it makes a combination between the personal and social emotions (Al-Samadoni, 2007). It was Bar-on who uses the concept of emotional intelligence for the first time instead of the Intelligence Quotient concept considered the emotional intelligence as a mixture or a set of skills, traits and social, personal and emotional capabilities that affect the person's ability of adaption under the environmental requirements and pressures.

Emotional intelligence components:

Goleman (1995) stated that emotional intelligence has five components classified in to two major dimensions:

First: the personal competences: these competences identified and determine the way we control and manage ourselves and they include the following:

- Self-awareness: it refers to recognize and understand one own moods and emotions that enable the person to take his own decisions.

- Self-regulation: it means controlling impulses and emotions and thinking before responding.

- Motivation: it refers to personal and emotional interest to achieve the goal.

Second: social competencies including:

- Empathy: it means the ability to understand other people's emotions, needs and interests.

- Social skills: the ability to identify social cues to establish desired responses. It is the person's own ability to communicate, guide and inspire others (Jerwan, 2012).

The relation between the emotional intelligence and the people with sensory impairments: the emotional intelligence is considered as one of the most important elements that help the people with disabilities to invest and utilize their effort and capabilities to the limit which in turn will help them understand themselves and others. It also helps their integration in the society and provides opportunities to overcome some problems facing them. In the same context, (Al Jawaldeh, 2012) showed that developing the emotional intelligence skills helps the children with hearing impairment to reduce the degree of their bullying. Learning the emotional intelligence skills allow the children to accept themselves and understand others. Wagner (2004) pointed that the social competencies of the people with visual impairment are the major component of people's positive self- awareness and high self-esteem. The study of Knutson (1990) cited in (Abd-Hameed, 2009) illustrated that the acquired deafness is mainly leads to psychological disorder and functions during their interaction with others represented by isolation and depression.

And many studies pointed that many people with hearing impairment are more vulnerable for psychological pressures and anxiety than their normal peers and there is a difference in terms of their effect on the individuals according to different elements (AL-Zregat, 2003, p. 181). Other studies showed a relation between the mothers' 
attitudes towards their children with visual impairment and their growth characteristics in addition to parents' responses including the personal adaption (Al Hadidi, 2013). The mental capabilities of the visual impaired people varied noticeably from one to another just like the normal people, therefore the low expectations of the visual impaired people should be avoided and they should be trained to get benefit of the remaining visual functions and to activate other senses as hearing (AL-Hadidi, 2009).

Based on the theoretical background, the researchers assured the significance of this study which is represented by identifying the emotional intelligence levels of the students with sensory disabilities looking for conducting further related studies to the results of the study and raising the emotional intelligence of the students with sensory disabilities.

\subsection{Previous Studies}

In her study, Hamid (2006) soak to identify the differences in the level of emotional intelligence between the students with visual impairment and the blind students in light of degree of impairment and gender variables. A sample consisted of 73 students with visual impairment aged from 10 to 19 years was chosen. Bar-on model of emotional intelligence and a questionnaire were used to collect data. Results showed statistical significant differences between the students with visual impairment and the blind students in the means of the emotional intelligence according to the degree of impairment variable in favor of blind students in the total degrees of the emotional intelligence and its sub-components. Moreover, results revealed statistical significant differences among the students with visual impairment in the means of the emotional intelligence according to the gender variable in favor of the females.

The study of Eniola and Busari (2014) aimed at revealing the level of the emotional intelligence and its role in enhancing self-motivation of the students with visual impairment at the university. Nineteen male and nine female students with visual impairment aged(18-23) were chosen as a sample of the study. To achieve the goals of the study, Schutte et al. test of the emotional intelligence was used and a self-efficacy scale was developed by the researchers. Results showed the level of the students with visual impairment was moderate and there was positive effect of the increase of the emotional intelligence in the students' self-efficiency.

Ataabadi, Yusefi, and Moradi (2014) conducted a study in Iran aimed to reveal the level of the emotional intelligence, the social skills, family communication, self-estimation and their predictive capability of the deaf students' academic achievement. The study was applied on a sample from private schools in Iran. For collecting data, the scales of Petrides and Furnham, social skills, family communication and self-estimation were all used. Results revealed showed that the deaf students' level of intelligence, social skills, family communication and their self-estimation was low. Results also revealed positive statistical correlation between the emotional intelligence and family communication in one hand and between the students' academic achievement, on the other hand but there were no statistical significant correlation between the social skills and academic achievement.

In India, Attri and Rai (2013) conducted a study aimed to reveal the level of the emotional intelligence of the visual impaired students in the schools. The sample of the study which consisted of 120 visual impaired students was selected randomly. To achieve the goals of the study, an emotional intelligence scale was developed by the researchers. Results showed the emotional intelligence level of the visual impaired and normal students was moderate and there were no differences in the level of the emotional intelligence of the visual impaired students attributed to the gender.

In their study, Ataabadi, Yusefi, and Moradi (2013) soak to reveal the level of the emotional intelligence, the social skills, self-estimation and its relation with family communication of the deaf and hard of hearing people. The sample of the study which consisted of 106 students was chosen randomly from the private schools at Isfahan city in Iran. Scales of the emotional intelligence, social skills, social communication and self-estimation were used to collect data. Results revealed that the deaf and hard hearing students' social skills and emotional intelligence level was moderate. Moreover, results revealed positive statistical significant correlation between family communication and the emotional intelligence, social skills and self-esteem.

The study of Mirzaei and Saeedi (2013) aimed at comparing the level of the emotional intelligence and personal traits between persons with low vision and normal ones. The sample of the study which $\mathrm{h}$ was selected randomly consisted of 18 males and 28 females in Tehran. Bar-on scale of the emotional intelligence and a developed personal trait scale were used to collect data. Results showed the level of the emotional intelligence of the students with visual impairment ranged from low to moderate while it was moderate for the normal students. Furthermore, results showed that people with disabilities are open minded while the normal people are neurotic. 
Kumar and Singh (2013) conducted a study in India to reveal the level of the emotional intelligence and psychology compatibility of the visual impaired and normal students. The study which was applied on a purposeful sample consisted of 150 visual impaired students and 150 normal students were selected from elementary and secondary schools. To achieve the study's goals, the developed compatibility scale by Sinha and Singh (1993) and the emotional intelligence scale of Mangal and Mangal (2004) were used to collect data. Results revealed the level of the emotional intelligence and the psychology compatibility of the visual impaired students was moderate while it's moderate to high for the normal students. There was positive correlation between the emotional intelligence and the psychology compatibility of the visual impaired and normal students. Additionally, there were differences in the level of the emotional intelligence and the psychology compatibility in favor of the normal students.

To reveal the emotional intelligence level of the deaf and hard of hearing students, Yasin, Bari, and Salubin (2012) conducted their study in Malaysia. The sample of the study which consisted of 148 male and female deaf and hard of hearing students was selected randomly from the private schools. To achieve the study's objectives, surveys and questionnaires were used to measure the students' emotional intelligence level.

Results showed the emotional intelligence level of the deaf and hearing impaired students was moderate. There were no differences in the emotional intelligence level attributed to gender. Moreover, there were differences in the emotional intelligence attributed to the grade variable in favor of the higher grade and there was positive correlation between the emotional intelligence and the academic achievement of the students. There was negative correlation between the increase of the emotional intelligence level and the behavior problems of the deaf and hearing impaired students.

In her study, Haghighatzade (2012) compared the level of the emotional intelligence of the deaf and normal students. The sample of the study which consisted of 30 deaf students and 30 normal ones was selected randomly from a set of integrated schools in Isfahan. The emotional intelligence scale was used for collecting data. Results revealed the moderate level of the emotional intelligence of the deaf students. There were differences in the level of the emotional intelligence between the deaf and the normal students in favor of the normal students.

The study of Vogel-Walcutt, Schastchneider, and Bowers (2011) aimed to identify the levels of the emotional and social intelligence of the hearing impaired elementary students. Twenty hearing impaired students and other twenty normal students were chosen randomly from the private education and normal schools as a sample of the study. The social and emotional intelligence scale and teacher's observation were used to collect data. Results showed differences in the level of the social and emotional intelligence between the deaf and normal students in favor of the normal students.

Eniola and Adebiyi (2007) conducted a study in Nigeria to identify the level of emotional intelligence and the capability to set goals of the visual impaired students. The study also aimed to identify the effect of remedial counseling program in improving the students' emotional intelligence and the capability to set goals. The sample of the study which was chosen randomly consisted of 32 visual impaired students from the special education schools. To collect data, a developed emotional intelligence scale was used in addition to the scale of the capability to set functional goals. Results revealed significant effect to the remedial counseling program based on improving the levels of motivation in increasing the level of the emotional intelligence and the ability to set functional goals of the visual impaired students.

Sharma's (2006) study aimed at identifying the level of the emotional stability and the emotional intelligence of the visual impaired students and its relation to their study habits. The sample of the study which was selected randomly consisted of 60 visual impaired students. To achieve the study's goals, the emotional stability of Sengupta and Singh and the Indian copy of Brown \& Holtzman's scale were used to collect data. Results showed that the level of the students' emotional stability was moderate and there was positive statistical significant effect of the increase of the level of the emotional stability of the students with visual impairment in the students' study positive habits.

A study conducted by Dyck, Farugia, Schochet, and Holmes-Brown (2004) aimed to identify the differences in the level of the emotional and social intelligence between vision and hearing impaired students. The sample of the study which was selected randomly consisted of 49 visual impaired students, 42 hearing impaired students and 72 students with no sensory impairment. Emotion Recognition Scales were used to collect data. Results showed differences in the emotion and social intelligence in favor of the students with no sensory impairment compared to vision and hearing impaired students. Results also showed differences in the level of the emotion and social intelligence between the vision and the hearing impaired students in favor of the vision impaired students. 


\subsection{Problem of the Study}

Despite of the growing interest of the people with sensory impairment, they still need more services and programs for the problems they face. One of these problems could be their emotional intelligence level as it affects many of their life's aspects and their adaption. And therefore, this study soak to identify the emotional intelligence levels of students with sensory impairment and to attract the people's attention who work on designing and implementing the programs of raising and improving the emotional intelligence level of this category.

\subsection{Questions of the Study}

1) What are the emotional intelligence levels of students with hearing disabilities in Amman?

2) What are the emotional intelligence levels of students with visual disabilities in Amman?

3) Are there differences between students with hearing disabilities and students with visual disabilities in the levels of the emotional intelligence?

\subsection{Significance of the Study}

- It provides a tool to reveal the levels of the emotional intelligence of students with sensory disabilities which will be help the scholars and researchers to conduct further studies that present scientific knowledge concerning different aspects of the emotional intelligence of the students with visual and hearing disabilities.

- The originality of the study itself through identifying to which extent the students with hearing and visual disabilities in Amman possesses the emotional intelligence and revealing the differences between these two disabilities in this field.

\subsection{Limitations of the Study}

- The study is limited to the students aged from 12 to 18 who are enrolled in the schools and centers of special education in Amman for the academic year 2016-2017

- The study's instrument

- The study's implementation.

- $\quad$ The study study's methodology

\subsection{Procedural Definitions}

- Emotional intelligence: Chemiss and Goleman (2000, p. 61) defined it as the individual's ability to recognize his feelings and those of others, in addition to his ability to create motivation and manage emotions properly within themselves with their relations with others. Procedurally, it is defined as the degree which the respondent gets in the emotional intelligence scale which was prepared by the researchers in this study.

- Hearing impairment: it is any type or degree of hearing loss that could be classified as mild, moderate, severe, or profound (Al-Zregat, 2013). Procedurally, it is defined as the students with hearing impairment who are enrolled. in the schools and centers of special education in Amman for the academic year 2015-2016

- Visual Impairment: the person who lost the ability to use his vision properly in his daily affairs is considered a person with visual impairment (Al-Hadidi, 2013). Procedurally, it is defined as the students with the visual impairment and enrolled in the schools and centers of special education in Amman for the academic year 2015-2016.

\section{Method}

The analytic and descriptive approach was used in this study.

The study's participants: the participants who were two hundred impaired students and enrolled in the special education schools and centers in Amman; 140 hearing impaired students and 60 vision impaired students were selected purposefully as it is illustrated in Table 1 . 
Table 1. Distribution of the participants of the study in Amman first directorate of education

\begin{tabular}{lc}
\hline Type of impairment & Freq. \\
\hline Hearing & 140 \\
Visual & 60 \\
Total & 200 \\
\hline
\end{tabular}

\subsection{Instrument of the Study}

To achieve the study's goals, the researchers prepared an emotional intelligence scale consisted of 32 items.

The scale components: the scale which consisted of 40 items in its initial copy was prepared after reviewing the theoretical literature and previous studies related to the study's subject as the studies (Al-Khawaja, 2013; Al-Moleli, 2011; Al-Aqeel, 2011; Hameed, 2006, in addition to foreign references as Mayer \& Salovey, 2000; Bar On, 1997). The scale's items were distributed to four fields.

\subsection{Scale Validity}

The initial copy of the scale was presented to a set of specialized arbitrators in the field of special education, psychology and counseling to express their views in terms of the items appropriateness to each field and language accuracy. There was an agreement to adopt $80 \%$ as criteria for accepting the item, eight items were deleted based on the arbitrators' suggestions.

The final copy of the scale consisted of 32 items distributed to four fields as follows:

First field: emotional knowledge (1-8 items)

Second field: emotion organization (9-16)

Third field: empathy (17-25)

Fourth field: (social competency (26-32).

\subsection{Scale Reliability}

Reliability was checked by using (t-Retest) method. The scale was applied twice on a sample consisted of 20 male and females students; 10 students with visual impairment and 10 students with hearing impairment. The reliability coefficient was also calculated by using Cronbach alpha as it is illustrated in the following table:

Table 2. Cronbach's alpha \& reliability of the fields and the total degree

\begin{tabular}{lcc}
\hline Field & Reliability & Internal consistency \\
\hline Emotional knowledge & 0.91 & 0.93 \\
Emotions organization & 0.93 & 0.92 \\
Sympathy & 0.88 & 0.91 \\
Social competency & 0.91 & 0.93 \\
Emotional intelligence & 0.91 & 0.95 \\
\hline
\end{tabular}

Table 2 showed that all coefficients are acceptable for the purpose of the study.

\subsection{The Scale Correction}

Fifth-Lickert scale was adopted: always (5), often (4), sometimes (3), rarely (2), never(1) to correct the students' responses. The highest grade was (160) and lowest was (32). To examine the levels of the emotional intelligence of the visual and hearing impaired students, the following equation:

Class length $=$ upper limit- lower limit $/ \mathrm{N}$ of classes $=1-5 / 3=1.33$

- $2.33=1+33+1$ so the items with means range from 1 to 2,33 indicating low level of the emotional intelligence of the visual and hearing impaired students

- $\quad 3.67=1.33+2.34$, therefore items' means ranges from 2.34 to 3.67 means that the visual and hearing impaired students' emotional intelligence level was moderate.

- $\quad 5=1.3+3.68$ and so the items with means range from 3.68 to 5 means that that the visual and hearing impaired students' emotional intelligence level was high. 


\subsection{Statistical Treatment}

- $\quad$ To answer the first and the second questions, means, standard deviations and the ratios were used.

- $\quad$ To answer the third and fourth questions, T-Test was used.

\section{Results and Discussion}

First question: What are the levels of the emotional intelligence of the students with hearing impairment in Amman?

To answer this question, the means and standard deviation were calculated as it is illustrated in Table 3.

Table 3. Means and standard deviations of the levels of the emotional intelligence of the students with hearing impairment

\begin{tabular}{lllccc}
\hline Rank & $\mathrm{N}$ & Field & $\mathrm{M}$ & $\mathrm{Std}$ & Level \\
\hline 1 & 3 & Eympathy & 1.93 & .563 & Low \\
2 & 4 & Social competency & 1.44 & .396 & Low \\
3 & 1 & Emotion knowledge & 1.39 & .352 & Low \\
3 & 2 & Emotion organization & 1.37 & .325 & Low \\
& & Emotional intellgence & 1.51 & .312 & Low \\
\hline
\end{tabular}

Table 3 showed that the means ranged from 1.37 to 1.93 . The empathy field came first with (1.94) while the emotion regulation field came last with (1.38). The researcher attributed this result to the failure of the students with hearing impairment in developing their emotional intelligence skills and as a result they are less interactive and communicative with others. And so their emotional maturity will be affected and their psychological stresses will hinder them from dealing with others' emotions.

Results of second question: What are the levels of the emotional intelligence of the visual impaired students?

To answer this question, means and standard deviations of the emotional intelligence levels of the visual impaired students in Amman were calculated as it is illustrated in the following table.

Table 4. Means and standard deviations of the emotional intelligence levels of the visual impaired students in Amman

\begin{tabular}{lllccc}
\hline Rank & N & Field & M & Std & Level \\
\hline 1 & 4 & Social efficency & 4.31 & .459 & High \\
2 & 3 & Sympathy & 3.97 & .386 & High \\
3 & 1 & Emotional knowledge & 3.26 & .295 & Moderate \\
4 & 2 & Emotions organization & 3.18 & .326 & Moderate \\
& & Emotional intellegence & 3.65 & .278 & Moderate \\
\hline
\end{tabular}

Table 4 showed that the means ranged from 3.18 to 4.3. The Social efficiency field came first with (4.31) while the emotions organization field came last with (3.18). The researchers attributed these results to their belief that sight loss does not delay any interaction and communication emotionally with others. The students with visual impairment have a level of emotional intelligence that enables them to interact with others' emotions in an acceptable manner.

Results of the third question: Are there differences between the visual and hearing impaired student in the emotional intelligence levels?

To answer this question, means and the standard deviations of the emotional intelligence levels of the visual and hearing impaired students were calculated and t-test was also used to reveal any statistical differences between the means as it is illustrated in the following table. 
Table 5. Means and the standard deviations of the emotional intelligence levels of the visual and hearing impaired students and t-test results

\begin{tabular}{llcccccc}
\hline & & $\mathrm{N}$ & $\mathrm{M}$ & $\mathrm{Std}$ & $\mathrm{T}$ & $\mathrm{FD}$ & Sig. \\
\hline \multirow{2}{*}{ Emotional knowledge } & Hearing & 140 & 1.38 & .351 & -37.050 & 210 & .000 \\
& Visual & 60 & 3.26 & .295 & & & \\
Emotions organizations & Hearing & 140 & 1.38 & .326 & -36.311 & 210 & .000 \\
& Visual & 60 & 3.18 & .326 & & & \\
\multirow{5}{*}{ Sympathy } & Hearing & 140 & 1.94 & .564 & -25.677 & 210 & .000 \\
\multirow{5}{*}{ Social competency } & Visula & 60 & 3.97 & .386 & & & \\
\multirow{4}{*}{ Emotional intellegnce } & Hearing & 140 & 1.43 & .395 & -45.808 & 210 & .000 \\
& Visual & 60 & 4.31 & .459 & & & \\
& Hearing & 140 & 1.52 & .312 & -46.461 & 210 & .000 \\
& Visual & 60 & 3.65 & .278 & & & \\
\hline
\end{tabular}

The previous table showed statistical significant differences at $(\mathrm{a}=0.05)$ between the visual and hearing impaired students in all the fields and in the total degree of the emotional intelligence in favor of the visual impaired students

According to the researchers, this result may due to the fact that the students with visual impairment are more capable to communicate with other than the people with hearing impairment as the ability to hear are considered a basic component to succeed any communication. Accordingly, this communication allows this category to achieve the highest degrees of emotional intelligence represented by social efficiency, emotional knowledge, emotion regulation, and empathy while the people with hearing impairment do not have the same opportunity to communicate with others for their hearing loss and so they have limited emotional growth and an introverted personality accompanied by low self-esteem.

\section{Recommendations}

- The necessity to encourage people with sensory disabilities to take part in well-prepared activities and programs that allow them to express their emotions freely as drawing, acting, music and others to develop their emotional intelligence.

- It is important to conduct further studies related to other patterns of intelligence concerning people with sensory disabilities as social intelligence.

- The necessity to support the role of the families and centers and help them to take their responsibility for the care of the people with sensory impairment to enable them feel secure and have psychological satisfaction so as to get to higher levels of emotional intelligence.

\section{References}

Abd-Hameed, S. (2009). Vision impairment. Dar Wafa for publishing and distribution, Alexanardia.

Al-Hadidi, M. (2009). Introduction in the vision impairment. Amman: Dar Fikr for publishing and distribution.

Al-Hadidi, M. (2013). Introduction in the people with special needs' education. Dar Fikr for publishing and distribution.

Al-Jawalda, F. (2012). The hearing impairment. Amman, Jordan: Dar Thagafa for publishing and distribution.

Al-Samadoni, A, I. (2007). Emotion intelligence: Its basics, applications and development. Amman: Dar Fikr for publishing and distribution.

Al-Zregat, I. (2003). Hearing impairment. Amman: Dar Wael for publishing and distribution.

Al-Zregat, I. (2009). Hearing impairment. Amman: Dar Fikr for publishing and distribution.

Ataabadi, S., Yousefi, Z., \& Moradi, A. (2013). Investigation of the multiple relations between emotional intelligence, social skills and self-esteem with family communications among deaf and hard of hearing adolescents. International Research Journal of Applied and Basic Sciences, 3(11), 1600-1608.

Attri, A., \& Rai, B. (2013). Emotional intelligence of visually impaired adolescents studying in inclusive and exclusive settings. Educational Research International, 1(2), 33-40.

Dyck, M. J., Farugia, C., Schochet, I. M., \& Holmes-Brown, M. (2004). Emotion recognition/understanding ability in hearing or vision-impaired children: Do sounds, Sights, or words make the difference? Journal of 
Child Psychology and Psychiatry, 45(4), 789-800. https://doi.org/10.1111/j.1469-7610.2004.00272.x

Eniola, M., \& Adebiyi, K. (2007). Emotional intelligence and goal setting- an investigation into interventions to increase motivation to work among visually impaired students in Nigeria. British Journal of Visual Impairment, 25(3), 249-253. https://doi.org/10.1177/0264619607079805

Eniolan, S., \& Busari, A. (2014). Emotional intelligence in promoting self-efficacy of the visually impaired fresh students of federal college of education (special) Oyo, Nigeria. International Journal of Humanities and Social Science, 4(14), 170-179.

Ghobari, A., \& Abo-Shaera, K. (2010). Mental capabilities between intelligence and creativity. Amman: Al-Mojtam Al-Arabi for publishing and distribution.

Goleman, D. (1995). Emotional intelligence: Why it can matter more than IQ. London, Bnloomsbury.

Haghighatzade, R. (2012). A comparison of the emotional intelligence two groups of deaf and non-deaf students in Isfahan. Journal of Basic and Applied, 2(9), 9573-9576.

Hamid, S. (2006). Studying the emotional intelligence of different samples of visual and hearing impaired preparatory and secondary students (Unpublished Thesis). Cairo University, and Education Studies Institution.

Jarwan, F. (2012). The emotional intelligence and the emotional social learning. Amman: Dar Fikr for publishing and distribution.

Kumar, S., \& Singh, J. (2013). Emotional intelligence and adjustment among visually impaired and sighted school students. Asian Journal of Multidimensional Research, 2(8), 1-8.

Mirzaei, S., \& Saeedi, R. (2013). Comparison of emotional intelligence and personality traits of the successful and normal individual with visual impairments in Tehran city. International Journal of Applied Psychology, $3(3), 83-87$.

Sharma, S. (2006). Emotional stability of visually disabled in relation to their study habits. Journal of the Indian Academy of Applied Psychology, 32(1), 30-32.

Soliman, A. (2007). Vision impaired people. Dar Zahra, Riyadh.

Taha, O. (2008). Efficiency of a counseling program for emotion intelligence development in reducing bullying of the students with hard hearing impairment (Unpublished dissertation). Cairo University, Education Studies Institution.

Tuttle, D. W., \& Tuttle, N. R. (1996). Self-esteem and adjusting with blindness. U.S.A: Charles C. Thomas.

Vogel-Walcutt, J., Schastchneider, C., \& Bowers, C. (2011). Social-Emotional functioning of elementary-age deaf children: A profile analysis. American Annals of the Deaf, 156(1), 6-22. https://doi.org/10.1353/aad.2011.0017

Wagner, E. (2004). Development and Implementation of A-curriculum To Develop Social Competence for Student with Visual Impairment in Germany. Journal of Visual Impairment \& Blindness, 98, 703-710.

\section{Copyrights}

Copyright for this article is retained by the author(s), with first publication rights granted to the journal.

This is an open-access article distributed under the terms and conditions of the Creative Commons Attribution license (http://creativecommons.org/licenses/by/4.0/). 